D.O.I.:10.3895/S1808-04482012000100006

\title{
A MELHORIA DA GESTÃO NA INDÚSTRIA DE PAPEL: ALINHANDO A METODOLOGIA DO BALANCED SCORECARD COM A GESTÃO DO CONHECIMENTO
}

\section{THE IMPROVING MANAGEMENT IN PAPER INDUSTRY: ALIGNMENT THE BALANCED SCORECARD METHODOLOGY WITH KNOWLEDGE MANAGEMENT}

\author{
Rita de Cassia Fonseca ${ }^{1}$; Marcia Danieli Szeremeta Spak $^{2}$; Camila Clivati Justus ${ }^{3}$; João Carlos \\ Colmenero ${ }^{4}$ \\ ${ }^{1}$ Universidade Estadual do Centro-Oeste - UNICENTRO - Guarapuava - Brasil \\ ritadecfonseca@hotmail.com \\ ${ }^{2}$ Universidade Tecnológica Federal do Paraná - UTFPR - Ponta Grossa - Brasil \\ marciaspak@yahoo.com.br \\ ${ }^{3}$ Universidade Tecnológica Federal do Paraná - UTFPR - Ponta Grossa - Brasil \\ milajustus@hotmail.com \\ ${ }^{4}$ Universidade Tecnológica Federal do Paraná - UTFPR - Ponta Grossa - Brasil \\ colmenero@utfpr.edu.br
}

\begin{abstract}
Resumo
Este trabalho tem por objetivo avaliar a metodologia de alinhamento do Balanced Scorecard (BSC) com a gestão do conhecimento, visando melhorias na qualidade da gestão. A pesquisa foi realizada em um Grupo Industrial, composto de três empresas, com foco na indústria de papel, aqui denominada Empresa Beta. Esta empresa possui o BSC como ferramenta de gerenciamento estratégico, o qual possibilitou o referido estudo. Após a realização da coleta dos dados, foi possível realizar a análise dos documentos e verificar a importância do alinhamento da Gestão do Conhecimento com a ferramenta do BSC. Identificaram-se os pontos para disseminação do conhecimento, em que é possível e necessário estabelecer novos objetivos e ações estratégicas para a empresa em estudo. Verificou-se que a aplicação do método BSC apresentou viabilidade de adaptação com a Gestão do Conhecimento para o tipo de empresa em estudo, como também os desdobramentos nas diversas perspectivas. O conjunto de indicadores do BSC elaborados $e$ ordenados nas diversas perspectivas, ligados aos objetivos da empresa, permite um controle mais amplo e efetivo, possibilitando desta forma que os colaboradores da empresa possam conhecer as estratégias e resultados esperados, como também as suas relações de causa e efeito. Assim, o estudo enfatiza a instrumentação corporativa para que possa ocorrer a conversão do conhecimento individual em estratégico de forma contínua.
\end{abstract}

Palavras-chave: gestão estratégica, gestão do conhecimento, balanced scorecard (BSC).

\section{Introdução}

O cenário atual sinaliza que a competitividade dos negócios e as mudanças no ambiente das empresas demandam a maximização do desempenho e o controle empresarial. Exige-se que as 
medidas de prevenção e controle do que se desenrola nos cenários internos e externos das organizações se modernize e incorpore as mudanças de mercado, tendo em vista que os sistemas e medidas tradicionais demonstram ineficácia. Esses modelos tradicionais são mais ligados aos aspectos financeiros e preocupam-se em avaliar custos, receita e lucro de acordo com padrões financeiros e contábeis. Todavia, nem sempre os indicadores criados refletem adequadamente o sucesso na definição e implementação de estratégias de interesse da empresa.

Diante disso, entende-se que as organizações necessitam cada vez mais de informações dinâmicas que atendam às novas exigências empresariais e auxiliem no processo decisório. Com isso, são necessárias melhorias contínuas em relação aos seus produtos e processos e também a ampliação da capacidade dos seus recursos de produção.

$\mathrm{Na}$ atualidade, observa-se o fácil acesso à tecnologia da informação e a abundância de informações, em contrapartida existe a dificuldade em filtrar as informações para entender a sua lógica intrínseca e conhecer a sintonia existente entre as informações gerenciais para transformá-las em diferencial competitivo. Nesse processo, as empresas vêm recorrendo a instrumentos de gestão para garantir sua competitividade no mercado em meio a tantas informações.

Existem muitas ferramentas para acompanhamento do desempenho das atividades nas organizações, entre elas destaca-se o Balanced Scorecard (BSC). O BSC é uma ferramenta de gestão que visa à integração e o balanceamento dos principais indicadores de desempenho existentes em uma empresa. É uma ferramenta destinada à avaliação de diversos aspectos organizacionais, fornece informações e medidas a serem tomadas para a melhoria do desempenho organizacional (WANG; ZHANG; ZENG, 2012).

Essa ferramenta originou-se nos trabalhos de Kaplan e Norton, e a partir de 1990 o uso do BSC vem crescendo entre as organizações, pois se trata de uma metodologia para a comunicação, acompanhamento, medição e análise da estratégia das empresas.

No contexto da competitividade, as organizações perceberam a importância de gerenciar o conhecimento para torná-las mais competitivas e conseqüentemente, aumentar sua rentabilidade. As empresas ao transformarem seus negócios em elementos que possam ser medidos e ao mesmo tempo associados à estratégia, possibilitam por meio de indicadores realizarem uma avaliação do grau de cumprimento de seus objetivos estratégicos.

Com o intuito de contribuir com empresas, este estudo discute a aplicabilidade de ferramentas de gestão, por meio do uso de instrumentos de medição de desempenho capazes de contribuir na elaboração de estratégias e no processo decisório das empresas, voltadas especificamente à indústria de papel. O objetivo deste trabalho é avaliar a metodologia de alinhamento do BSC com a gestão do conhecimento, com vistas a difundir melhorias na qualidade da gestão em indústrias de papel. A investigação é realizada em uma empresa no ramo de produção 
de papel e celulose no estado do Paraná, aqui denominada Empresa Beta.

\section{Referencial teórico}

\subsection{Gestão estratégica}

Um dos maiores desafios enfrentados pelas organizações é se manterem competitivas no mercado, para isso devem ser desenvolvidas estratégias eficazes visando o alcance dos objetivos. A estratégia é um conjunto de áreas de conhecimento que aplicadas corretamente, trabalham em função do alcance dos resultados esperados.

Para a obtenção de uma boa estratégia é importante a análise profunda das variáveis envolvidas, cumprir determinadas etapas do processo e acompanhá-las permite assegurar o alcance dos resultados esperados. As etapas estruturadoras das estratégias dependem de cada situação proposta e das variáveis envolvidas no processo. Para tanto, a estratégia somente poderá ser desenvolvida por meio de análises que compreendam todas as variáveis envolvidas (MINSTZBERG; QUINN, 1991; MONTGOMERY; PORTER, 1998).

A estratégia é um plano que integra as principais metas, políticas e a sequência de ações de uma organização como um todo. Uma estratégia bem formulada ajuda a ordenar e alocar os recursos de uma organização de forma coerente. A estratégia pode ser visualizada com a construção de defesas contra forças competitivas. O conhecimento das capacidades da empresa e das causas das forças competitivas destacará as áreas nas quais a empresa deve confrontar a competição e as quais deve evitá-las (MINSTZBERG; QUINN, 2000; MONTGOMERY; PORTER, 1998).

Anthony e Govindarajan (2002) definem a estratégia na qual a sua formulação resulta de um processo empregado pela alta administração para avaliar os pontos fortes e fracos da empresa à luz das oportunidades e dos riscos existentes. Após essa avaliação são definidas as estratégias condizentes com as capacidades fundamentais da organização com vistas ao aproveitamento das oportunidades que o ambiente apresenta. A gestão estratégica destaca a influência de decisões passadas sobre as atuais e futuras, transformando a gestão num processo evolutivo que enriquece as medidas tomadas pelas organizações ao longo do tempo (LAMBERG; PARVINEN, 2003).

Embora haja algumas diferenças entre as definições de estratégia, há um consenso segundo o qual a estratégia descreve a direção geral de planejamento de uma organização para atingir seus objetivos. Uma empresa determina suas estratégias por meio da comparação entre as suas capacidades fundamentais e as oportunidades existentes.

As estratégias de uma empresa podem ser de nível corporativo em que a sua definição engloba a organização como um todo, e as estratégias específicas para cada setor da organização. As estratégias específicas de cada setor dependem de dois aspectos interligados: a missão, determinando quais são os seus objetivos, e a vantagem competitiva, o modo como o setor deve 
desempenhar a sua atividade para cumprir a missão, criando assim uma cadeia de valor dentro da empresa (PORTER 1999; WRIGHT; KROLL; PARNELL, 2000; ANTHONY; GOVINDARAJAN, 2002).

O planejamento é um conjunto de ações desenvolvidas para alcançar as metas comuns da empresa e determinar os objetivos, estruturando a melhor forma de atingi-los. Assim, há uma concentração de esforços e utilização dos recursos de forma mais eficiente (KRONMEYER, 2006). Desta forma, no ambiente organizacional, o planejamento estratégico dever ser claramente definido, dando sustentação ao alcance dos objetivos e direcionando o rumo da empresa.

\subsection{Balance Scorecard (BSC)}

As críticas aos sistemas tradicionais de controle que consideram somente os indicadores financeiros e a falta de ligação entre estratégia e operações, fez com que os estudos caminhassem em busca de solução para tais problemas. Kaplan e Norton (1997) tomaram a direção para chegar a uma medida multidimensional, indicando as características de equilíbrio entre medidas de curto e de longo prazo, entre medidas financeiras e não financeiras, entre indicadores de tendência e indicadores de ocorrência e entre perspectivas internas e externas de desempenho, surgindo assim a ferramenta BSC.

O BSC propõe de forma objetiva equilibrar as medidas organizacionais, traduzindo a missão e a estratégia das organizações em um conjunto que abrange as medidas de desempenho servindo de base para a gestão estratégica e enfatizando a busca de objetivos financeiros. Desta forma, o BSC constitui um sistema de gestão estratégica com a proposta de auxiliar as organizações a traduzir suas estratégias em ação. O BSC auxilia as organizações otimizando a visão estratégica e alinhando as atividades com as medidas de desempenho organizacional, visando o cumprimento das metas pré-definidas (FAROOQ; HUSSAIN, 2011).

O processo de construção do BSC evidencia os objetivos estratégicos organizacionais. O BSC mede o desempenho organizacional sob quatro perspectivas básicas: perspectiva financeira, perspectivas de clientes, perspectivas de processos internos e perspectivas de aprendizado e crescimento. Essa medição baseia-se numa série de relações de causa e efeito advindas da estratégia e estima o grau de correlação entre as medidas dos indicadores. O termo "Balanced" evidencia o equilíbrio das quatro perspectivas caracterizadas pelas suas abordagens, incorporando um conjunto de medidas genéricas integradas vinculadas ao desempenho (KAPLAN; NORTON, 2001).

Wang, Zhang, Zeng (2012) afirmam que a ponderação das quatro perspectivas pode formar um método preciso de compreensão e execução das estratégias organizacionais. A composição do BSC deve ser coerente com a estratégia da organização alinhando iniciativas individuais, organizacionais e interdepartamentais, visando traduzir a estratégia em objetivos e medidas 
tangíveis para garantir o seu alcance. Para atingir esses objetivos devem ser definidos indicadores e metas alinhadas as iniciativas, de maneira que quando executadas marquem o cumprimento das metas e os objetivos de longo prazo da empresa.

\subsection{Gestão do conhecimento}

A gestão do conhecimento surgiu a partir da necessidade das organizações em aprimorarem suas capacidades de inovação na tomada de decisão e incrementarem a efetividade de seus processos organizacionais. Essa necessidade foi evidenciada principalmente pelo atual contexto econômico e social, caracterizado pelo incremento da competição, o acréscimo da dinamicidade nos mercados, dos ciclos mais curtos de desenvolvimento de produtos e o aumento das exigências dos consumidores (CASTILLO; CAZARINI, 2009).

A gestão do conhecimento vem ganhando destaque entre as organizações devido à necessidade de diferenciação nos mercados competitivos, sua implantação coordenada torna-se uma vantagem organizacional. $\mathrm{O}$ conhecimento é orientado à ação e assim a gestão do conhecimento deve promover a execução de ações alinhadas com os objetivos estratégicos da empresa. Segundo Gao, Li e Clarke (2008) A gestão do conhecimento está diretamente ligada a clareza dos objetivos organizacionais, a gestão eficaz do conhecimento depende da mobilização do capital humano para o alcance dos objetivos.

Davenport (1998) destaca que o conhecimento é uma mistura fluída de experiências agrupadas, valores e informações o qual proporciona uma estrutura para avaliação e incorporação de novas experiências. Nas organizações, a gestão do conhecimento costuma estar ligada não somente ao conhecimento, mas também as rotinas, processos, práticas e normas organizacionais.

A Gestão do Conhecimento significa organizar as principais políticas, processos e ferramentas gerenciais e tecnológicas para uma melhor compreensão dos processos de geração, identificação, validação, disseminação, compartilhamento e uso dos conhecimentos estratégicos, gerando assim resultados numéricos para a organização, assim como benefícios para os colaboradores. Esses processos são variáveis que as organizações enfrentam para alcançar seus objetivos e a administração dos diversos níveis de conhecimento permite que uma organização alcance os objetivos propostos pela alta direção (TERRA, 2007).

Conforme exposto por Fairchild (2002), a gestão do conhecimento é um conjunto de processos de transferência de valor ao capital intelectual. Está diretamente relacionada à geração, inovação, aquisição, organização e aplicação de conhecimentos. Sendo assim, a Gestão do Conhecimento é direcionada a administração do capital intelectual da organização, visando o constante aprendizado e crescimento organizacional.

\subsection{O Balanced Scorecard (BSC) e a gestão do conhecimento}


As empresas buscam cada vez mais vantagens competitivas que são baseadas em recursos intangíveis como o conhecimento, o relacionamento com os clientes, serviços inovadores, habilidades, competências e motivação dos colaboradores. Uma grande dificuldade está em gerenciar esses recursos intangíveis, pois torna-se necessário a utilização de uma ferramenta que permita descrever os ativos com base no conhecimento e estratégias de valor construídas a partir desses ativos.

Com o desenvolvimento do Balanced Scorecard, apresenta-se um sistema estruturado para integrar medidas de desempenho e análise de informações com a missão e estratégia das companhias, focando o desempenho organizacional sob quatro perspectivas: financeira, clientes, processos e aprendizado e crescimento. Nesse processo, o BSC formula as hipóteses sobre a cadeia de causa e efeito, levando ao sucesso no nível estratégico.

Kaplan e Norton (1997) destacam a importância da dimensão aprendizado e crescimento e reconhecem que os vetores dessa perspectiva são mais genéricos e menos desenvolvidos que das demais perspectivas. A geração responsável de um BSC, que estabelece metas e indicadores coerentes e alinhados com as estratégias, mostrará a participação do capital intelectual das organizações.

O capital intelectual é o resultado da comparação do conhecimento com os objetivos econômicos. Assim, a aplicação do conhecimento impacta no valor das organizações, pois a utilização desse recurso em conjunto com as tecnologias disponíveis e capital humano, produzem benefícios intangíveis que agregam valor (DAVEMPORT ; PRUSAK, 1998).

Desta forma, a gestão do conhecimento está voltada para o capital humano que é composto pelo conhecimento, o poder de inovação e habilidade dos empregados e ainda podem ser considerados os valores e a cultura da empresa.

A gestão do conhecimento deve sustentar os conhecimentos aplicáveis nas atividades estratégicas que são identificadas nos indicadores e vetores do BSC, distribuídas em todas as perspectivas. Assim, a perspectiva de aprendizado e crescimento é vetor de resultados nas três outras perspectivas, compondo a base de aprimoramento da gestão da empresa, pois é a base que possibilita a consecução nas demais perspectivas (KAPLAN; NORTON, 1997).

$\mathrm{Na}$ relação de causa e efeito, o objetivo final de todas as perspectivas do BSC são os resultados financeiros e que tem como ponto de partida a perspectiva de aprendizado e crescimento a qual engloba a Gestão do Conhecimento.

\section{Metodologia}

A pesquisa classifica-se como exploratória e descritiva, quanto a natureza é considerada aplicada. Quanto a abordagem do problema é considerada qualitativa por tratar de particularidades e 
interpretações individuais, em relação aos procedimentos técnicos é considerada um estudo de caso representado por uma indústria de papel no centro-oeste do Paraná.

Os instrumentos de coleta de dados utilizados foram entrevista não estruturada e pesquisa documental. As entrevistas foram realizadas com o gerente financeiro, gerente de recursos humanos, coordenador de tecnologia da informação (TI) e colaboradores do sistema integrado de gestão (SIG). As entrevistas geraram dados primários utilizados nas descrições e análise da pesquisa. A segunda etapa foi a pesquisa documental, realizada em documentos e relatórios fornecidos pela empresa, os quais foram avaliados e utilizados nas análises dos resultados.

\section{Estudo de caso}

O estudo foi realizado em uma empresa de médio porte, aqui denominada empresa Beta. A escolha da referida empresa deu-se pela acessibilidade, e devido a empresa possuir o BSC como ferramenta de gerenciamento da estratégia, o qual possibilitou o referido estudo.

A Empresa Beta atua há mais de 30 anos nos segmentos de papel e como diferencial estratégico tem autossuficiência energética, proporcionada por hidrelétricas próprias. Atualmente, o grupo é formado por cinco empresas, que atuam nos ramos de papel e celulose, agricultura e reflorestamento.

A partir do ano de 2004, a empresa Beta passou a se preocupar com o reconhecimento das estratégias da empresa. Até então, o conhecimento empírico predominava na empresa. Assim, embora resistisse à elaboração formal de suas estratégias passou a se preocupar em registrá-las, após as constatações de ideias novas de gestores e com a ativa participação de um dos sócios, houve o convencimento para implantação do BSC na empresa. Dessa forma, ocorreu o amadurecimento das estratégias com a observação da necessidade de capacitação dos colaboradores, implantação de novos projetos, implantação de programas de qualidade como o 5S e TPM (Total Productive Managements), aumento da capacidade das máquinas entre outros.

Com a implantação do TPM na área de produção de papel, os diretores puderam observar a necessidade de investimentos voltados à gestão e formulação de estratégias para a empresa como um todo. Nesse processo, verificou-se a necessidade do planejamento estratégico onde a estrutura foi desenvolvida buscando a eficácia operacional e a busca de um diferencial para atender as necessidades dos clientes.

A hierarquia das responsabilidades do planejamento dentro da organização nos níveis estratégico, tático e operacional é definida de acordo como o processo gerencial de desenvolvimento e manutenção e entre os objetivos e os recursos da empresa, assim como as mudanças e oportunidades de mercado. O objetivo do planejamento estratégico é a orientação dos negócios da empresa de modo que gere lucros e crescimento satisfatórios. 
Os níveis de planejamento estratégico da Empresa Beta definem a direção que a organização deve seguir e como chegar aos resultados esperados, como mostra a figura 1.

Figura 1 - Estrutura dos níveis de planejamento estratégico

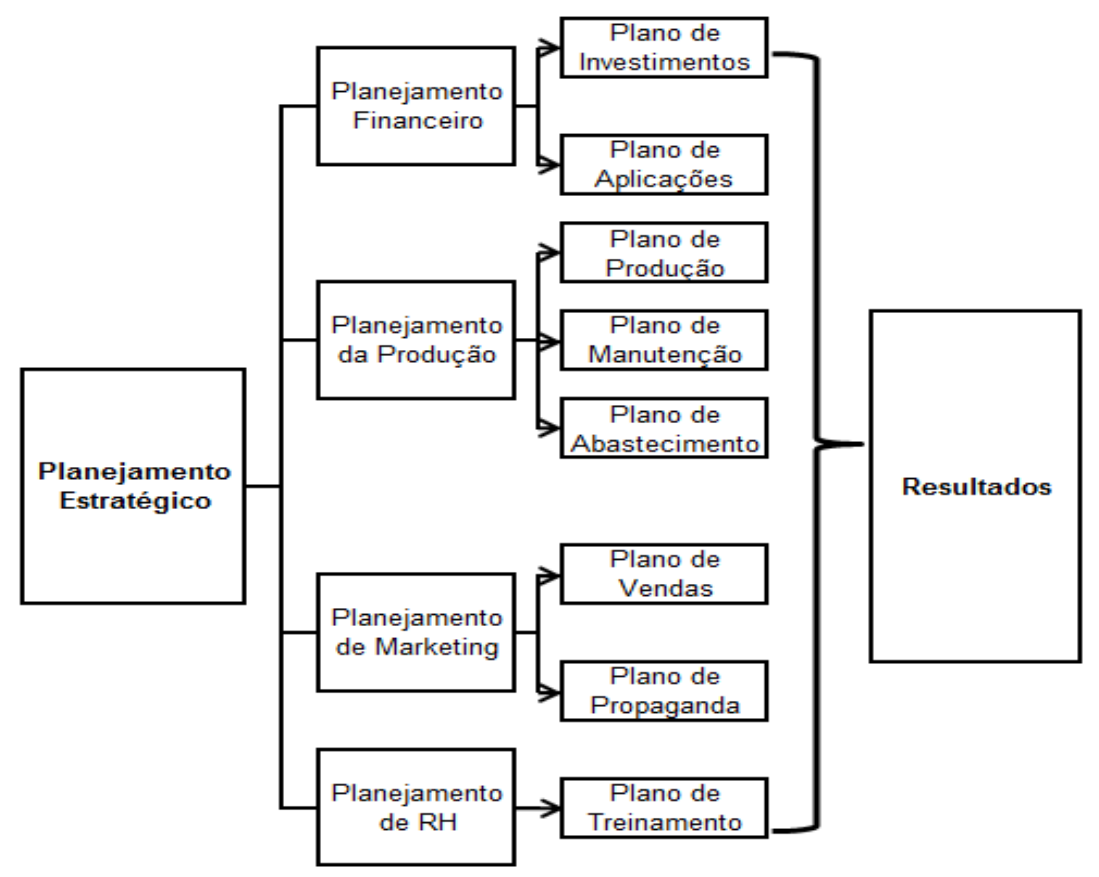

Fonte: Empresa Beta (2010)

Para o planejamento financeiro são tratados os planos de investimentos e os planos de aplicações dos recursos. Já no Planejamento de Produção é considerado o plano de produção, de manutenção e de abastecimento. Para o planejamento de marketing são levados em consideração o plano das vendas e de propaganda, ficando sob responsabilidade do planejamento de recursos humanos toda a parte de treinamentos dos colaboradores da empresa.

Com a contratação de uma consultoria, a Empresa Beta passou a formalizar suas estratégias, criando sua própria estrutura. A estrutura montada parte de análises fundamentais, estudos visionários, análise de SWOT e pesquisas de interesse com pessoas relacionadas a empresa como: acionistas, fornecedores, clientes e colaboradores. A estrutura do Planejamento Estratégico da Empresa Beta é apresentada na Figura 2. 
Figura 2 - Estrutura do planejamento estratégico

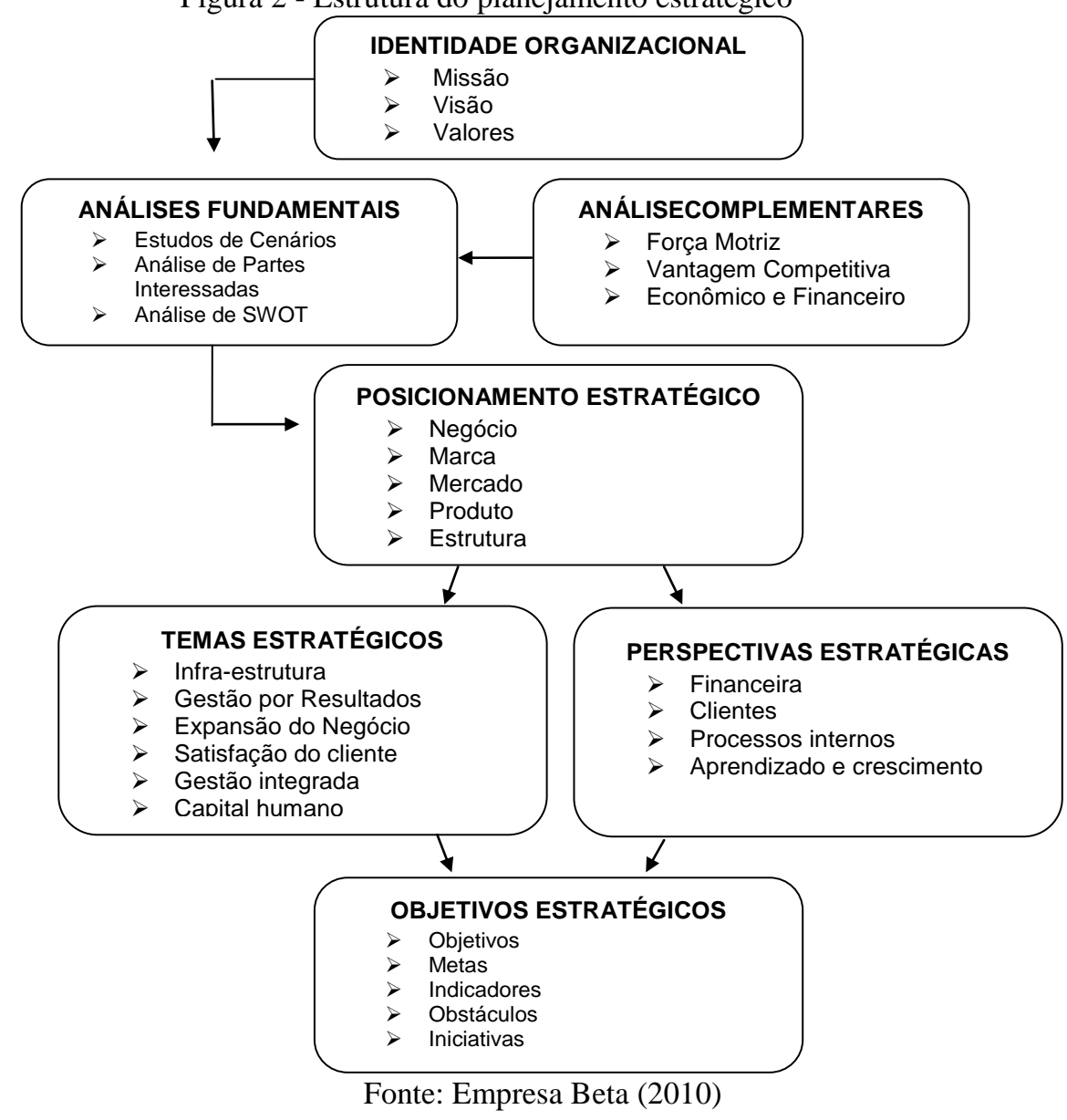

Com as análises realizadas, partiu-se para determinação dos indicadores a serem utilizados na ferramenta BSC. O contato com os colaboradores determinou os indicadores a serem utilizados na perspectiva de aprendizado e crescimento. Destacou-se o posicionamento da empresa, detalhando o alinhamento para ações individuais e para a concentração no foco pela busca de resultados.

Dessa forma, a opção pela ferramenta BSC auxiliou a empresa Beta na gestão de sua estratégia, no planejamento, na sua execução e controle, traduzindo a estratégia aos níveis operacionais. Assim o BSC é executado e controlado a partir dos mapas estratégicos e utilizado na integra para garantir os resultados.

A missão e visão são praticadas por toda a empresa, respeitando todos os níveis hierárquicos, onde a estratégia é apresentada de cima para baixo e os resultados conseguidos de baixo para cima. Assim, o BSC representa a comunicação, esclarecimento e alinhamento de todas as áreas e objetivos, com todos os projetos da organização. Os diretores da empresa Beta puderam observar a possibilidade de construir uma estratégia diferenciada e competitiva, transformar essa estratégia em ação, integrando processos e inovando para o alcance da eficácia.

\subsection{Detalhamento do projeto}


O Projeto de utilização da ferramenta BSC iniciou-se com a necessidade de formalizar o seu planejamento estratégico, assim foi criado um departamento integrado de gestão, que formalizou e implantou a ferramenta na empresa. O detalhamento estratégico abrange uma hierarquia dos colaboradores para que se cumpram os objetivos da organização de cima para baixo, onde cada gestor de cada unidade ou departamento é responsável pela definição das metas que deverão ser buscadas pelos colaboradores imediatamente abaixo na cadeia hierárquica.

A composição do BSC consiste em determinar objetivos em cada parte da cadeia hierárquica para chegar à cultura desejada. São iniciadas nos níveis mais altos da organização para seguir o desdobramento e atingir os objetivos propostos. O projeto do BSC na empresa Beta definiu a composição de uma rotina envolvendo a gestão estratégica:

Definir a missão, visão e valores: a criação da missão, visão e determinação de valores da organização deve ser definida de forma que todos os envolvidos no processo, colaboradores, acionistas, fornecedores e sociedade, compreendam a sua importância e coloquem em prática sua filosofia.

Elaborar o planejamento estratégico: a elaboração do mesmo faz parte das tarefas do nível estratégico da organização, é um conjunto flexível de informações consolidadas que serve de referência guiando as ações organizacionais. Na elaboração do planejamento estratégico da Empresa Beta foram considerados: a formulação dos objetivos da organização; análise das condições internas da empresa para permitir uma avaliação dos principais pontos fortes e fracos que a organização possui; avaliação de desempenho da empresa em termos de lucratividade, produção, produtividade, inovação, crescimento e desenvolvimento dos negócios; análise das condições externas que envolvem os clientes, concorrentes e a conjuntura econômica; formulação das alternativas estratégicas que a organização pode adotar para alcançar os objetivos organizacionais.

Executar o planejamento estratégico utilizando o BSC: para que se cumprisse o planejamento estratégico, utilizou-se a ferramenta Balanced Scorecard que busca alinhar e avaliar os processos. Assim são desenvolvidos os mapas estratégicos e o desdobramento dos objetivos estratégicos.

Controlar a execução do planejamento estratégico: o controle se concentra no monitoramento e avaliação do processo de estratégica no sentido de melhorá-lo, assegurando um funcionamento adequado. Dessa forma, o controle é feito através do contrato de indicadores estratégicos, reunião mensal de indicadores, revisões no desdobramento estratégico e plano diretor para alteração de metas.

\subsection{Mapa estratégico da empresa Beta}

O mapa estratégico da Empresa Beta foi desenvolvido com base nos temas estratégicos 
determinados pela alta direção e assim é dividido em corporativo, papel e florestal. O foco neste trabalho é a unidade papel. O mapa estratégico da Empresa Beta tem a representação visual das relações de causa e efeito entre os componentes da estratégia, para visualização das ações. $\mathrm{Na}$ Figura 3, é apresentado o mapa estratégico da unidade de papel, responsável por atingir $69 \%$ do EBITDA corporativo.

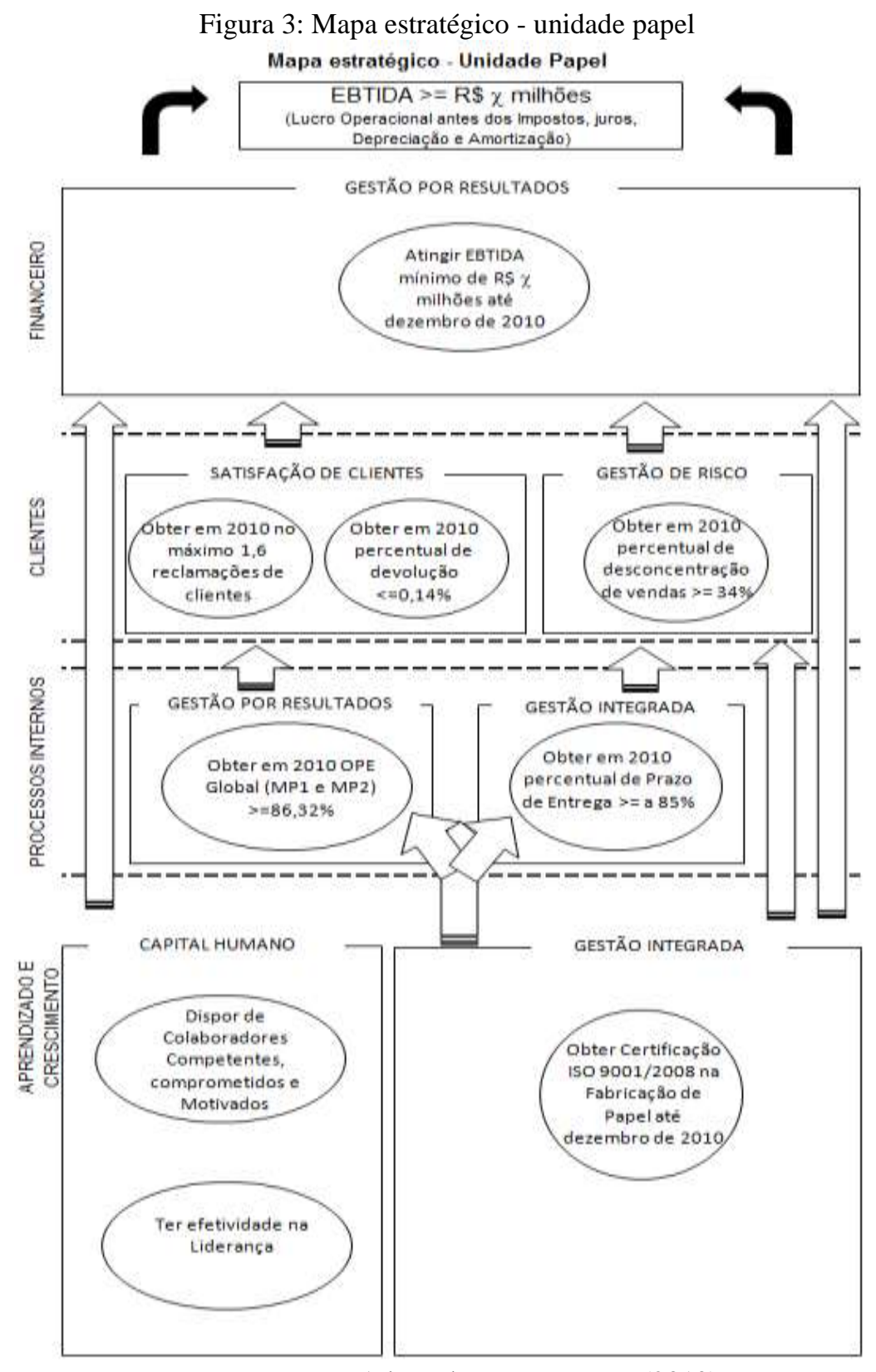

Fonte: Adaptado empresa Beta (2010)

Para a consolidação do objetivo da perspectiva financeira, as relações de causa e efeito da perspectiva de clientes são consideradas no tema satisfação de clientes, com indicadores de quantidade de reclamações, e devoluções do produto. Para o tema gestão de risco é medido o percentual de desconcentração de vendas, com a maior desconcentração, menor será o risco para a empresa, pois estará aumentando o número de clientes.

A gestão por resultados, na perspectiva de processos internos está relacionada à obtenção da 
eficiência da produção, procurando atingir um percentual mais próximo de $100 \%$ e está diretamente ligada ao tema satisfação de clientes na perspectiva de clientes. O tema gestão integrada, também na perspectiva de processos internos, considera o percentual do cumprimento dos prazos de entrega na totalidade dos clientes, atingindo diretamente o tema gestão de riscos da perspectiva clientes.

Na perspectiva de aprendizado e crescimento, são apresentados os temas capital humano e gestão integrada, considerando os objetivos de capacitação de pessoas e também a obtenção da certificação da norma ISO 9001/2008 necessitando de conhecimentos específicos para a implementação na unidade papel.

\subsection{Desdobramentos dos objetivos estratégicos}

O desdobramento estratégico para a unidade papel é composto pelos objetivos estratégicos presentes no mapa estratégico, os indicadores de cada objetivo, as iniciativas e seus respectivos indicadores que compõem cada objetivo, além dos responsáveis para cada iniciativa conforme apresentado no quadro 1. Cada iniciativa possui um setor responsável que irá implementar as ações correspondentes aos objetivos buscando as soluções necessárias que serão medidas pelos indicadores propostos.

Quadro 1: Desdobramento dos objetivos estratégicos - unidade papel.

\begin{tabular}{|c|c|c|c|c|c|c|c|c|}
\hline \multicolumn{9}{|c|}{ DESDOBRAMENTO DOS OBJETIYOS ESTRATEGICOS - PAPEL } \\
\hline \multicolumn{2}{|c|}{ MAPA } & OBJETIYO ESTRATÉGICO & INDICADOR & RESPONSAYEL & $\mathbf{N}$ & INICIATIYA & INDICADOR & RESPONSAYEL \\
\hline \multirow{7}{*}{$\begin{array}{l}\mathbf{F} \\
\mathbf{I} \\
\mathbf{N} \\
\mathbf{A} \\
\mathbf{N} \\
\mathbf{C} \\
\mathbf{E} \\
\mathbf{I} \\
\mathbf{R} \\
\mathbf{D}\end{array}$} & \multirow{7}{*}{1} & \multirow{7}{*}{$\begin{array}{c}\text { OBTER EBITDA }>=\text { R\$ MILHÖES ATE } \\
\text { DEZEMBRO DE } 2010\end{array}$} & \multirow{7}{*}{ EBITDA. } & \multirow{7}{*}{ DIRETOR 1} & 1 & $\begin{array}{c}\text { OBTER EM } 2010 \text { CPV <= RS } \\
\text { \% MLHÖES }\end{array}$ & CPV & GERENTE PRODUÇ.\&O \\
\hline & & & & & 2 & $\begin{array}{c}\text { OBTER EM } 2010 \text { CUSTO } \\
\text { MÉDIO TOTALL DE } \\
\text { PRODUÇ., }<=\text { R } \$ \text { \&TON }\end{array}$ & $\begin{array}{l}\text { CUSTO TOTALL DE } \\
\text { PRODUÇ\&Ot TON }\end{array}$ & GERENTE PRODUÇĂO \\
\hline & & & & & 3 & $\begin{array}{l}\text { OBTER EM 2010 PRECCO } \\
\text { MEDIO LIQUUIDO>= R\$\% } \\
\text { PITON }\end{array}$ & PREÇO LÍQUIDO & $\begin{array}{l}\text { GERENTE } \\
\text { COMERCIALL }\end{array}$ \\
\hline & & & & & 4 & $\begin{array}{l}\text { OBTER EM 2010 DESPESA } \\
\text { OPERRACIONAL } \\
\text { ADMINISTRATIVA }<=\text { RA\% } \\
\text { MIIHOHES }\end{array}$ & $\mathrm{DOA}$ & $\begin{array}{l}\text { GERENTE } \\
\text { FINA,NCEIRO }\end{array}$ \\
\hline & & & & & 5 & $\begin{array}{c}\text { OBTER EM 2010 DESPESA } \\
\text { OPERA,CIONALL COMERCIAL, } \\
\langle=\text { R\$MILHÖES }\end{array}$ & 000 & \multirow{3}{*}{$\begin{array}{l}\text { GERENTE } \\
\text { COMERICIAL }\end{array}$} \\
\hline & & & & & 6 & $\begin{array}{c}\text { OBTEREM EM } 2010 \\
\text { FATURAMENTOERIUTO >= } \\
\text { R\$\%MILHÖES }\end{array}$ & $\begin{array}{c}\text { FATURAMENTO } \\
\text { BRIUTO }\end{array}$ & \\
\hline & & & & & 7 & $\begin{array}{c}\text { FA,TURA,AR EM VOLUME EM } \\
2010>=\angle \text { TON }\end{array}$ & $\begin{array}{l}\text { YOLUME DE } \\
\text { WENDAS }\end{array}$ & \\
\hline \multirow{6}{*}{$\begin{array}{l}\mathbf{C} \\
\mathbf{L} \\
\mathbf{I} \\
\mathbf{E} \\
\mathbf{N} \\
\mathbf{T} \\
\mathbf{E} \\
\mathbf{S}\end{array}$} & 2 & $\begin{array}{c}\text { OBTERPERCENTUAL DE } \\
\text { DESCONCENTRAC,\&ODE VENDAS } \\
>=34 \% \text { EM DEZEMBRODE } 2010\end{array}$ & \begin{tabular}{|l|} 
CONCENTRAR $80 \%$ \\
DAS VENDAS EM $34 \%$ \\
DOS CLIENTES
\end{tabular} & GERENTE COMERICIAL & - & . & . & - \\
\hline & \multirow{5}{*}{3} & \multirow{5}{*}{$\begin{array}{l}\text { OBTER EM } 2010 \text { ÍNDICE MÁXIMODE } \\
\text { RECLAMAÇCOES DE CLIENTES }\end{array}$} & \multirow{5}{*}{\begin{tabular}{|} 
REECLAMACCOOES DE \\
CLIENTES ACA.TADASH \\
1000 TON FATURA.DAS
\end{tabular}} & \multirow{5}{*}{$\begin{array}{l}\text { COORDENADORDA } \\
\text { QUALLIDADE }\end{array}$} & 1 & $\begin{array}{l}\text { MP1: OBTER EM 2010 NO } \\
\text { MAXXIMO 0,\%DAS } \\
\text { RECLAMAÇOES } \\
\text { ACATADASACADA 1000 } \\
\text { TONFATURADAS }\end{array}$ & \begin{tabular}{|c|} 
N.DE \\
RECLAMACOES \\
ACATADAST 1000 \\
TONFATURADAS \\
\end{tabular} & \multirow{3}{*}{$\begin{array}{l}\text { COORDENA,DOR DE } \\
\text { PRODUÇ\&OO }\end{array}$} \\
\hline & & & & & 2 & $\begin{array}{l}\text { MP2: OBTEREM } 2010 \text { NO } \\
\text { MA,XIMO 0,\%DAS } \\
\text { RECLAMACCOES } \\
\text { ACATADAS A.CADAA, } 1000 \\
\text { TONFATURADAS }\end{array}$ & $\begin{array}{c}\text { N.DE } \\
\text { RECLAMAÇOES } \\
\text { ACATADAST } 1000 \\
\text { TONFATURADAS } \\
\end{array}$ & \\
\hline & & & & & 3 & 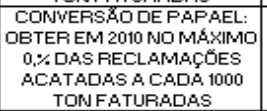 & \begin{tabular}{|c|} 
N.DE \\
RECLAMAÇOES \\
ACATADAST 1000 \\
TON FATURADAS \\
\end{tabular} & \\
\hline & & & & & 4 & $\begin{array}{l}\text { MP1: OBTER EM 2010 NO } \\
\text { MAXIMO 0.\%DAS } \\
\text { RECLAMACCOES } \\
\text { ACATADASACADA } 1000 \\
\text { TON FATURADAS }\end{array}$ & \begin{tabular}{|c|}
$\mathrm{N} \cdot \mathrm{DE}$ \\
RECLAMACCOES \\
ACATADASH 1000 \\
TONFATURADAS \\
\end{tabular} & $\begin{array}{l}\text { GERENTE DE } \\
\text { LOGISTICA. }\end{array}$ \\
\hline & & & & & 5 & $\begin{array}{l}\text { LOGÍSTICA: OBTER EM 2010 } \\
\text { NOMAXMMO 0\% OAS } \\
\text { RECLAMAÇOES } \\
\text { ACATADASA.CADA. } 1000 \\
\text { TON FATURADAS }\end{array}$ & \begin{tabular}{|c|}
$N \cdot D E$ \\
RECLAMACCOES \\
ACATADASH 1000 \\
TONFATURADAS \\
\end{tabular} & $\begin{array}{l}\text { GERENTE } \\
\text { COMERCIA,L }\end{array}$ \\
\hline
\end{tabular}




\begin{tabular}{|c|c|c|c|c|c|c|c|c|}
\hline \multicolumn{9}{|c|}{ DESDOBRAMENTO DOS OBJETIYOS ESTRATÉGICOS - PAPEL } \\
\hline MA & $\mathrm{PA}$ & OBJETIYO ESTRATEGICO & INDICADOR & RESPONSAYEL & $\mathbf{N}$ & INICIATIYA & INDICADOR & RESPONSAYEL \\
\hline \multirow{7}{*}{$\begin{array}{l}\mathbf{C} \\
\mathbf{L} \\
\mathbf{I} \\
\mathbf{E} \\
\mathbf{N} \\
\mathbf{T} \\
\mathbf{E} \\
\mathbf{S}\end{array}$} & \multirow{3}{*}{3} & \multirow{3}{*}{$\begin{array}{l}\text { OBTER EM } 2010 \text { íNDICE MAXXIMO DE } \\
\text { RECLAMMAÇÓES DE CLIENTES }\end{array}$} & \multirow{3}{*}{$\begin{array}{l}\text { RECLAMAÇÖES DE } \\
\text { CLIENTES ACATADASH } \\
1000 \text { TON FATURA.DAS }\end{array}$} & \multirow{3}{*}{$\begin{array}{l}\text { COORDENA.DORDA } \\
\text { QUALIDA.DE }\end{array}$} & 6 & $\begin{array}{l}\text { TRATARR NO MÍNIMO } 75 \% \\
\text { DAS RECLAMACCOES } \\
\text { TECNICASE GENERICAS EM } \\
\text { TEMPO }<=15 \text { DIASS }\end{array}$ & \begin{tabular}{|c|} 
N.DE \\
RECLAMACOOS \\
ACATADASH 1000 \\
TONFATURADAS \\
\end{tabular} & \multirow[b]{3}{*}{ ANALISTA } \\
\hline & & & & & 7 & $\begin{array}{l}\text { CUMPRIMENTODO } \\
\text { CRONOGRAMA }\end{array}$ & $\begin{array}{c}100 \% \text { DO } \\
\text { CRONOGRAMA }\end{array}$ & \\
\hline & & & & & 8 & $\begin{array}{c}\text { ATINGIR 92\% NO NÍVEL DE } \\
\text { SATISFAÇAODO CLIENTE } \\
\text { ENTRE BOME OTIMO } \\
\text { CONFORME PESQUISA.DE } \\
\text { SATISFAÇ.8ODE } \\
\text { ATENDIMENTO } \\
\text { RECLAMAÇÖES POS- } \\
\text { VENDAS }\end{array}$ & $\begin{array}{l}\text { RESULTADODA } \\
\text { PESQUISADE } \\
\text { SATISFAÇAODE } \\
\text { CLIENTENO } \\
\text { ATENDIMENTO } \\
\text { RECLAMACOCOES } \\
\text { POS VENDAS } \\
\end{array}$ & \\
\hline & \multirow{4}{*}{4} & \multirow{4}{*}{$\begin{array}{l}\text { OBTERPERCENTUA,L DE } \\
\text { DEVOLUÇ,.O }<=0,14 \% \text { EM } 2010\end{array}$} & \multirow{4}{*}{$\begin{array}{l}\text { \%DE PAPPEL } \\
\text { DEVOLVIDOEM } \\
\text { RELACC,AOA } \\
\text { QUANTIDADE } \\
\text { FATURADA }\end{array}$} & \multirow{4}{*}{$\begin{array}{l}\text { COORDENA.DORDA } \\
\text { QUALIDA.DE }\end{array}$} & 1 & $\begin{array}{l}\text { MP1: OBTER EM } 2010 \text { NO } \\
\text { MAXXIMODE 0,0\%DE } \\
\text { DEVOLUÇ\&ODE PAPEL }\end{array}$ & $\begin{array}{l}\text { \%DEPAPEL } \\
\text { DEVOLVIDOEM } \\
\text { RELAC,AOA } \\
\text { QUANTIDADE } \\
\text { FATURADA }\end{array}$ & \multirow{2}{*}{$\begin{array}{l}\text { COORDENA.DORIDE } \\
\text { PRODUÇAOO }\end{array}$} \\
\hline & & & & & 2 & $\begin{array}{l}\text { MP2: OBTEREM } 2010 \text { NO } \\
\text { MAXXIMODE } 0,0 \% \text { DE } \\
\text { DEVOLUÇ\&ODE PAPEL }\end{array}$ & $\begin{array}{l}\text { \%DEPAPEL } \\
\text { DEVOLVIDOEM } \\
\text { RELACC.AOA } \\
\text { QUANTIDADE } \\
\text { FATURADA }\end{array}$ & \\
\hline & & & & & 3 & $\begin{array}{l}\text { LOGÍSTICA: OBTER EM } 2010 \\
\text { NOMAXXIMODE 0,0\%DE } \\
\text { DEVOLUÇ,.,ODE PAPEL }\end{array}$ & $\begin{array}{l}\text { \%DEPAPEL } \\
\text { DEVOLVIDOEM } \\
\text { RELAÇAOA A } \\
\text { QUANTIDADE } \\
\text { FATURADA }\end{array}$ & GERENTE LOGÍSTICA \\
\hline & & & & & 4 & \begin{tabular}{|c|} 
COMERCIAL: OBTER EM \\
2010 NO MAXXIMO DE 0,0\%DE \\
DEVOLUÇ,\&OOE PAPEL
\end{tabular} & $\begin{array}{l}\text { \%DEPAPEL } \\
\text { DEVOLVIDOEM } \\
\text { RELAC,AOA A } \\
\text { QUANTIDADE } \\
\text { FATURA.DA. }\end{array}$ & $\begin{array}{l}\text { GERENTE } \\
\text { COMERCIA.L }\end{array}$ \\
\hline \multirow{6}{*}{$\begin{array}{l}\mathbf{P} \\
\mathbf{R} \\
\mathbf{0} \\
\mathbf{C} \\
\mathbf{E} \\
\mathbf{S} \\
\mathbf{S} \\
\mathbf{0} \\
\mathbf{S}\end{array}$} & \multirow{4}{*}{5} & \multirow{4}{*}{$\begin{array}{c}\text { OBTER EM } 2010 \text { OPE GLOBA.L (MP1E } \\
\text { MP2) }>=86,22 \%\end{array}$} & \multirow{4}{*}{ OPE (GLOBAL) } & \multirow{4}{*}{$\begin{array}{l}\text { GERENTE DE } \\
\text { PROOUÇ,O }\end{array}$} & 1 & $\begin{array}{l}\text { OBTER PRODUÇ,8O } \\
\text { EFETIVA }>=\% \text { TON } 2010\end{array}$ & $\begin{array}{l}\text { PRODUÇ.\&O } \\
\text { EFETIVA }\end{array}$ & $\begin{array}{l}\text { GERENTEDE } \\
\text { PRODUÇ, } \\
\end{array}$ \\
\hline & & & & & 2 & \begin{tabular}{|l} 
IMPLEMENTAR TPMNO \\
PAPEL VISANDO A.META \\
DE XX,XX\% DE OPE GLOBAL
\end{tabular} & $\begin{array}{l}\text { OBTER } 90 \% \text { NA } \\
\text { AUDITORIA } \\
\text { MENSAL }\end{array}$ & COORDENADORSIG \\
\hline & & & & & 3 & $\begin{array}{c}\text { OBTERDISPONIBILIDADEE } \\
\text { OPERACIONALL NA, MPI }>= \\
98 \% \text { EM } 2010\end{array}$ & \begin{tabular}{|c|} 
\%DE \\
DISPONIBLIDA.DE \\
DE OPERACIONA.L
\end{tabular} & \multirow{2}{*}{$\begin{array}{l}\text { COORDENADORDE } \\
\text { PRODUÇ.SO }\end{array}$} \\
\hline & & & & & 4 & $\begin{array}{c}\text { OBTERDISPONIBILIDADEE } \\
\text { OPERACIONAL NA MP2 } 2>= \\
98 \% \text { EM } 2010 \\
\end{array}$ & \begin{tabular}{|c|} 
\%DE \\
DISPONIBILIDA.DE \\
DE OPERACIONA.L \\
\end{tabular} & \\
\hline & \multirow[t]{2}{*}{6} & \multirow[t]{2}{*}{$\begin{array}{c}\text { OBTER PERCENTUAL DE PRA,ZO DE } \\
\text { ENTREGA DE }>=85 \% \text { EM } 2010\end{array}$} & \multirow[t]{2}{*}{ PRA.ZO DE ENTREGA } & \multirow[t]{2}{*}{$\begin{array}{l}\text { GERENTE DE } \\
\text { LOGÍSTICA }\end{array}$} & 1 & $\begin{array}{l}\text { PRODUÇ,AO: CUMPRIR } \\
\text { PRA.ZODE PRODUÇ,AO } \\
\text { PROGRAMADO }\end{array}$ & \begin{tabular}{|c|}
$100 \%$ DAS ACCOES \\
COMDATA \\
PREVISTA ATE \\
DEZEMBRO DE \\
2010 \\
IMPLEMENTADAS \\
\end{tabular} & $\begin{array}{l}\text { GERENTEDE } \\
\text { PRODUÇ,OO }\end{array}$ \\
\hline & & & & & 2 & $\begin{array}{c}\text { COMERCIAL: EFETIVAR } \\
\text { VENDAS COMBASE NA } \\
\text { PROGRAMACCAO }\end{array}$ & & $\begin{array}{l}\text { GERENTE } \\
\text { COMERCIA.L }\end{array}$ \\
\hline \multirow{7}{*}{$\begin{array}{l}\hat{A} \\
\mathbf{P} \\
\mathbf{R} \\
\mathbf{E} \\
\mathbf{W} \\
\mathbf{D} \\
\mathbf{1} \\
\mathbf{Z} \\
\hat{\mathbf{D}} \\
\mathbf{0} \\
\mathbf{E}\end{array}$} & \multirow{5}{*}{7} & \multirow{5}{*}{$\begin{array}{c}\text { OBTER CERTIFICADOO ISO 900112008 } \\
\text { NA. FABRICAC,AODE PAPEL ATE } \\
\text { DEZEMBRO } 2010\end{array}$} & \multirow{5}{*}{$\begin{array}{c}\text { EMPRESA } \\
\text { CERTIFICADA ATE } \\
\text { DEZEMBRODE } 2010\end{array}$} & \multirow{5}{*}{ COORDENADORSIG } & 1 & $\begin{array}{l}\text { QUALIDA.DE: DESENVOLVER } \\
\text { DOCUMENTACC,OO } \\
\text { NECESSARFIA }\end{array}$ & $\begin{array}{c}\text { N.DE N\&,O } \\
\text { CONFORMIDA.DE } \\
\text { MAIOR }\end{array}$ & $\begin{array}{c}\text { COORDENA.DORDA } \\
\text { QUA.LIDA.DE }\end{array}$ \\
\hline & & & & & 2 & $\begin{array}{c}\text { PRODUCC,OO: DESENYOLVER } \\
\text { DOCUMENTACC,OO } \\
\text { NECESSA.RIA }\end{array}$ & $\begin{array}{c}\text { N.DE N\&., } \\
\text { CONFORMIDA.DE } \\
\text { MAIOR }\end{array}$ & $\begin{array}{l}\text { GERENTE DA } \\
\text { PRODUÇAOO }\end{array}$ \\
\hline & & & & & 3 & $\begin{array}{c}\text { CONERCIAL: DESENVOLVER } \\
\text { DOCUMENTACC,OO } \\
\text { NECESSARARA }\end{array}$ & $\begin{array}{c}\text { N.DE N\&,O } \\
\text { CONFORMIDA.DE } \\
\text { MAIOR }\end{array}$ & $\begin{array}{l}\text { GERENTE } \\
\text { COMERCIA.L }\end{array}$ \\
\hline & & & & & 4 & $\begin{array}{l}\text { SUPRIMENTOS: } \\
\text { DESENVOLVER } \\
\text { DOCUMENTAÇARO } \\
\text { NECESSARAIA }\end{array}$ & $\begin{array}{c}\text { N.DE N\&,O } \\
\text { CONFORMIDA.DE } \\
\text { MAIOR } \\
\end{array}$ & $\begin{array}{l}\text { GERENTE DE } \\
\text { LOGÍSTICA. }\end{array}$ \\
\hline & & & & & 5 & $\begin{array}{c}\text { RH:DESENWOLVER } \\
\text { DOCUMENTAÇ,AO } \\
\text { NECESSARARA }\end{array}$ & $\begin{array}{c}\text { NDE N\&, } \\
\text { CONFORMIDA.DE } \\
\text { MA.IOR } \\
\end{array}$ & GERENTE DE RH \\
\hline & \multirow{2}{*}{8} & \multirow{2}{*}{$\begin{array}{c}\text { DISPOR COLABORA,DORES } \\
\text { COMPROMETIDOS, MOTIVADOSE } \\
\text { COMPETENTES }\end{array}$} & \multirow{2}{*}{$\begin{array}{l}\text { 100\% DAS INICIATIVAS } \\
\text { DENTRO DA.META }\end{array}$} & \multirow{2}{*}{$\begin{array}{l}\text { GERENTE DE } \\
\text { QUALLIDADE }\end{array}$} & 1 & $\begin{array}{c}\text { OBTER PERCENTUALLDE } \\
\text { COLABORA,DORES } \\
\text { TREINA.DOS X PLANAJAA.DO } \\
>=93 \%\end{array}$ & \begin{tabular}{|c|} 
COLABORA,DORES \\
TREINA,DOS \\
PLANEJJADOS
\end{tabular} & GERENTE DE RH \\
\hline & & & & & 2 & $\begin{array}{c}\text { OBTEREM } 2010 \text { TAXA DE } \\
\text { FREQUENCIA DE } \\
\text { ACIDENTES }<=11 \\
\text { ACIDENTES }\end{array}$ & $\begin{array}{l}\text { TAXADE } \\
\text { FREQUENCIA, DE } \\
\text { ACIDENTES }\end{array}$ & $\begin{array}{l}\text { COORDENADORA } \\
\text { SEGUURANÇADO } \\
\text { TRABALLO }\end{array}$ \\
\hline
\end{tabular}

Fonte: Adaptado empresa Beta (2010)

\subsection{Manutenção e controle do Balanced Scorecard}

A manutenção do projeto consiste em definir as revisões dos objetivos estratégicos das metas e dos indicadores de desempenho. Assim, na Empresa Beta para a manutenção do BSC, ocorre a concentração do controle no monitoramento e avaliação do processo de estratégia para que sempre esteja atualizado garantindo que seu funcionamento seja adequado. As formas de 
monitoramento do processo estratégico da Empresa Beta ocorrem através de:

Contrato de Indicadores Estratégicos: consiste no detalhamento dos indicadores que serão usados durante o período de avaliação do desempenho. Neste contrato constam a forma como serão compostos os indicadores e as variáveis que serão utilizadas para avaliação. No processo de contrato dos indicadores são definidas as formas de cálculos que serão utilizadas para a mensuração do desempenho, a intenção de se considerar tais indicadores, as metas mensais que serão consideradas durante o ano e o histórico de anos anteriores para uma comparação com os resultados alcançados.

No contrato de indicadores são apresentados os objetivos estratégicos, qual indicador será utilizado para sua medição e o colaborador responsável por tal indicador. Os indicadores são definidos no início do período, rigorosamente planejados com antecedência para que durante todo o período sejam utilizados da forma como foi definido, não permitindo que sejam feita alterações, salvo em ocasiões que se comprove sua necessidade através de documentação.

O contrato de indicadores representa a formalização das ações que devem ser seguidas para determinar de que forma os colaboradores devem agir no presente, para atingir os objetivos esperados no futuro. Cada objetivo possui um ou mais indicadores de desempenho, onde sua função é demonstrar se a ação para atingir o objetivo está no caminho correto.

Reunião mensal de indicadores: reuniões mensais com a diretoria são realizadas para mostrar os resultados alcançados, onde todos os gerentes de áreas dentro da hierarquia são convocados para apresentação de seus resultados.

Plano Diretor para alteração de metas: conforme o andamento dos resultados e adequação das medições poderá ser solicitado algumas alterações de metas. Tais alterações podem ser realizadas, por meio de solicitações seguindo os passos do Plano Diretor de alteração de metas, em que os motivos são expostos através de documentos escolhidos pelo solicitante sejam por planilhas, normas ou qualquer documento que apresente os fundamentos dos motivos à solicitação. A solicitação passará por uma análise do comitê de análise de metas que é formado pelo departamento de recursos humanos, setor integrado de gestão e controladoria. Após a análise é enviado um parecer à diretoria da empresa que fará sua validação.

Revisões de desdobramento estratégico: anualmente são realizadas as revisões para determinações e reavaliações dos objetivos estratégicos da empresa. Na comparação entre as metas projetadas e realizadas, obtém-se a resposta sobre o andamento do desempenho da empresa. Caso alguma meta não seja atingida, o responsável pelo indicador deverá realizar uma ação corretiva para combater a causa raiz do problema e evitar sua repetição.

\subsection{Resultados do BSC na empresa}


Os dados aqui apresentados partiram da revisão realizada para o ano de 2010, onde são considerados os resultados obtidos até o mês de setembro com perspectivas até o final do período. O Quadro 2 apresenta os resultados obtidos até o mês de setembro na unidade papel na forma de porcentagens, relacionados com os desdobramentos estratégicos propostos na revisão do ano de 2010. Os resultados dos desdobramentos estratégicos da unidade papel são apresentados nas quatro perspectivas do BSC em que cada perspectiva contém a referência do indicador utilizado, suas iniciativas e o respectivo resultado obtido. 
Quadro 2 - Resultados obtidos unidade papel

\begin{tabular}{|c|c|c|c|c|c|c|}
\hline \multicolumn{7}{|c|}{ RESULTADOS OBTIDOS - PAPEL } \\
\hline \multicolumn{2}{|c|}{ MAPA } & OBJETIVO ESTRATÉGICO & INDICADOR & $\mathbf{N}$ & INICIATIVA & RESULTADOS OBTIDOS ATÉ 30/09/2010 \\
\hline \multirow{7}{*}{$\begin{array}{c}\mathrm{F} \\
\mathrm{I} \\
\mathrm{N} \\
\mathrm{A} \\
\mathrm{N} \\
\mathrm{C} \\
\mathrm{E} \\
\mathrm{I} \\
\mathrm{R} \\
\mathrm{O}\end{array}$} & \multirow{7}{*}{1} & \multirow{7}{*}{$\begin{array}{c}\text { OBTER EBITDA }>=\text { RS MILHÕES ATÉ } \\
\text { DEZEMMBRO DE } 2010\end{array}$} & \multirow{7}{*}{ EBITDA } & 1 & $\begin{array}{c}\text { OBTER EM } 2010 \mathrm{CPV}<=\text { RS } 96 \\
\text { MILHÕES }\end{array}$ & $65 \%$ \\
\hline & & & & 2 & $\begin{array}{c}\text { OBTER EM } 2010 \text { CUSTO MÉDIO } \\
\text { TOTAL DE PRODUÇÄO }<=\text { RS } 96 / \text { TON }\end{array}$ & $89 \%$ \\
\hline & & & & 3 & $\begin{array}{l}\text { OBTER EM } 2010 \text { PREÇO MÉDIO } \\
\text { LÍQUIDOs= RS } 96 \text { P/TON }\end{array}$ & $96 \%$ \\
\hline & & & & 4 & $\begin{array}{c}\text { OBTER EM } 2010 \text { DESPESA } \\
\text { OPERACIONAL ADMINISTRATIVA }<= \\
\text { RS } 96 \text { MILHÕES }\end{array}$ & $74 \%$ \\
\hline & & & & 5 & $\begin{array}{c}\text { OBTER EM } 2010 \text { DESPESA } \\
\text { OPERACIONAL COMERCIAL }<=\text { RS } \\
\text { MILHÕES }\end{array}$ & $72 \%$ \\
\hline & & & & 6 & $\begin{array}{l}\text { OBTER EM } 2010 \text { FATURAMENTO } \\
\text { BRUTO }>=\text { RS } 96 \text { MILHÕES }\end{array}$ & $64 \%$ \\
\hline & & & & 7 & $\begin{array}{l}\text { FATURAR EM VOLUME EM } 2010>=96 \\
\text { TON }\end{array}$ & $61 \%$ \\
\hline \multirow{12}{*}{$\begin{array}{c}\mathrm{C} \\
\mathrm{L} \\
\mathrm{I} \\
\mathrm{E} \\
\mathrm{N} \\
\mathrm{T} \\
\mathrm{E} \\
\mathrm{S}\end{array}$} & 2 & $\begin{array}{c}\text { OBTER PERCENTUAL DE } \\
\text { DESCONCENTRAÇÃO DE VENDAS }>= \\
\text { 3496 EM DEZEMBRO DE } 2010\end{array}$ & $\begin{array}{l}\text { CONCENTRAR } 8096 \\
\text { DAS VENDAS EM } \\
3496 \text { DOS CLIENTES }\end{array}$ & - & - & $\begin{array}{c}\text { CONCENTRAÇÃO DE } 77 \% \text { NOS } 34 \% \text { DOS } \\
\text { CLIENTES }\end{array}$ \\
\hline & \multirow{7}{*}{3} & \multirow{7}{*}{$\begin{array}{l}\text { OBTER EM } 2010 \text { ÍNDICE MÁXIMO } \\
\text { DE RECLAMAÇÕES DE CLIENTES }\end{array}$} & \multirow{7}{*}{$\begin{array}{l}\text { RECLAMAÇÕES DE } \\
\text { CLIENTES } \\
\text { ACATADAS/ } 1000 \\
\text { TON FATURADAS }\end{array}$} & 1 & $\begin{array}{c}\text { MP1: OBTER EM } 2010 \text { NO MÁXIMO } \\
\text { 0,96 DAS RECLAMAÇÕES ACATADAS A } \\
\text { CADA. } 1000 \text { TON FATURADAS }\end{array}$ & $72 \%$ \\
\hline & & & & 2 & $\begin{array}{c}\text { MP2: OBTER EM } 2010 \text { NO MÁXIMO } \\
\text { O,96 DAS RECLAMACCÕES ACATADAS A } \\
\text { CADA } 1000 \text { TON FATURADAS }\end{array}$ & $73 \%$ \\
\hline & & & & 3 & $\begin{array}{c}\text { CONVERSÃO DE PAPAEL: OBTER EM } \\
2010 \text { NO MÁXIMO O,96 DAS } \\
\text { RECLAMAÇÕES ACATADAS A CADA } \\
\text { 100O TON FATURADAS } \\
\end{array}$ & $65 \%$ \\
\hline & & & & 4 & $\begin{array}{c}\text { MP1: OBTER EM } 2010 \text { NO MÁ́XIMO } \\
\text { O,96 DAS RECLAMACCÕES ACATADAS A } \\
\text { CADA } 1000 \text { TON FATURADAS }\end{array}$ & $65 \%$ \\
\hline & & & & 5 & $\begin{array}{c}\text { LOGÍSTICA: OBTER EM } 2010 \text { NO } \\
\text { MÁXIMO 0,96 DAS RECLAMAÇÕES } \\
\text { ACATADAS A CADA. } 1000 \text { TON } \\
\text { FATURADAS }\end{array}$ & 20 dias \\
\hline & & & & 6 & $\begin{array}{c}\text { CUMPRIMENTO DO CRONOGRAMA } \\
\text { DE ATENDIMENTO PÓS-VENDA }\end{array}$ & 100\% DO CRONOGRAMA \\
\hline & & & & 7 & $\begin{array}{l}\text { ATINGIR } 9296 \text { DO NÍVEL DE } \\
\text { SATISFAÇÃO DO CLIENTE ENTRE BOM } \\
\text { EÓTIMO CONFORME PESQUISA DE } \\
\text { SATISFAÇÃO DE ATENDIMENTO } \\
\text { RECLAMAÇÕES PÓS-VENDAS }\end{array}$ & 6496 \\
\hline & \multirow{4}{*}{4} & \multirow{4}{*}{$\begin{array}{c}\text { OBTER PERCENTUAL DE } \\
\text { DEVOLUÇ,̃̈O }<=0,1496 \text { EM } 2010\end{array}$} & \multirow{4}{*}{$\begin{array}{l}\text { 96 DE PAPPEL } \\
\text { DEVOLVIDO EM } \\
\text { RELAÇÄOA A } \\
\text { QUANTIDADE } \\
\text { FATURADA }\end{array}$} & 1 & $\begin{array}{l}\text { MP1 : OBTER EM } 2010 \text { NO MÁXIMO } \\
\text { DE 0,096 DE DEVOLUÇÃO DE PAPEL }\end{array}$ & $72 \%$ \\
\hline & & & & 2 & $\begin{array}{l}\text { MP2: OBTER EM } 2010 \text { NO MÁ́xIMO } \\
\text { DEO, O96 DE DEVOLUÇÃO DE PAPEL }\end{array}$ & $73 \%$ \\
\hline & & & & 3 & $\begin{array}{c}\text { LOGÍSTICA: OBTER EM } 2010 \text { NO } \\
\text { MÁXIMO DE O,O96 DE DEVOLUÇÃAO } \\
\text { DE PAPEL }\end{array}$ & $65 \%$ \\
\hline & & & & 4 & $\begin{array}{c}\text { COMERCIAL: OBTER EM } 2010 \text { NO } \\
\text { MÁXIMO DE O,OSG DE DEVOLUÇÃOO } \\
\text { DE PAPEL }\end{array}$ & $65 \%$ \\
\hline \multirow{6}{*}{$\begin{array}{ll}\mathrm{P} & \\
\mathrm{R} & 1 \\
\mathrm{O} & \mathrm{N} \\
\mathrm{C} & \mathrm{T} \\
\mathrm{E} & \mathrm{E} \\
\mathrm{S} & \mathrm{R} \\
\mathrm{S} & \mathrm{N} \\
\mathrm{O} & \mathrm{O} \\
\mathrm{S} & \mathrm{S}\end{array}$} & \multirow{4}{*}{5} & \multirow{4}{*}{$\begin{array}{c}\text { OBTER EM } 2010 \text { OPE GLOBAL (MP1 } \\
\text { E MP2) }>=8696\end{array}$} & \multirow{4}{*}{$\begin{array}{l}\text { PRODUÇÃO EFETIVA } \\
\text { GLOBAL }\end{array}$} & 1 & $\begin{array}{c}\text { OBTER PRODUÇÃO EFETIVA }>=96 \text { TON } \\
2010\end{array}$ & $75 \%$ \\
\hline & & & & 2 & $\begin{array}{c}\text { IMPLEMENTAR TPM NO PAPEL } \\
\text { VISANDO A META. DE XX,XX96 DE OPE } \\
\text { GLOBAL }\end{array}$ & $95 \%$ \\
\hline & & & & 3 & $\begin{array}{l}\text { OBTER DISPONIBILIDADE } \\
\text { OPERACIONAL NA MP } 1>=9896 \mathrm{EM} \\
2010 \\
\end{array}$ & $96 \%$ \\
\hline & & & & 4 & $\begin{array}{c}\text { OBTER DISPONIBILIDADE } \\
\text { OPERACIONAL NA MP } 2>=9896 \text { EM } \\
2010 \\
\end{array}$ & $98 \%$ \\
\hline & \multirow{2}{*}{6} & \multirow{2}{*}{$\begin{array}{l}\text { OBTER PERCENTUAL DE PRAZO DE } \\
\text { ENTREGA DE }>=8596 \text { EM } 2010\end{array}$} & \multirow{2}{*}{ PRAZO DE ENTREGA } & 1 & $\begin{array}{l}\text { PRODUÇÃO: CUMPRIR PRAZO DE } \\
\text { PRODUÇÃO PROGRAMADO }\end{array}$ & $70 \%$ \\
\hline & & & & 2 & $\begin{array}{c}\text { COMERCIAL: EFETIVAR VENDAS COM } \\
\text { BASE NA PROGRAMAÇÃO }\end{array}$ & $70 \%$ \\
\hline \multirow{7}{*}{\begin{tabular}{|cc}
$A$ & \\
$P$ & $C$ \\
$R$ & $R$ \\
$E$ & $E$ \\
$N$ & $S$ \\
$D$ & $C$ \\
1 & $C$ \\
$Z$ & $M$ \\
$A$ & E \\
$D$ & $N$ \\
$O$ & $T$ \\
& $T$ \\
$E$ & 0
\end{tabular} \mid} & \multirow{5}{*}{7} & \multirow{5}{*}{$\begin{array}{c}\text { OBTER CERTIFICADO ISO } \\
9001 / 2008 \text { NA FABRICACCÃO DE } \\
\text { PAPEL ATÉ DEZEMBRO } 2010\end{array}$} & \multirow{5}{*}{$\begin{array}{c}\text { EMPRESA } \\
\text { CERTIFICADA ATÉ } \\
\text { DEZEMBRO DE } 2010\end{array}$} & 1 & $\begin{array}{l}\text { QUALIDADE: DESENVOLVER } \\
\text { DOCUMENTAÇÃO NECESSÁRIAA }\end{array}$ & $100 \%$ \\
\hline & & & & 2 & $\begin{array}{c}\text { PRODUÇÃO: DESENVOLVER } \\
\text { DOCUMENTAÇÄO NECESSÁRIA }\end{array}$ & $100 \%$ \\
\hline & & & & 3 & $\begin{array}{l}\text { CONERCIAL: DESENVOLVER } \\
\text { DOCUMENTAÇÃO NECESSÁRIAA }\end{array}$ & $100 \%$ \\
\hline & & & & 4 & $\begin{array}{l}\text { SUPRIMENTOS: DESENVOLVER } \\
\text { DOCUMENTAÇÄAO NECESSÁRIAA }\end{array}$ & $100 \%$ \\
\hline & & & & 5 & $\begin{array}{c}\text { RH :DESENVOLVER DOCUMENTAÇÃO } \\
\text { NECESSÁRIA }\end{array}$ & $100 \%$ \\
\hline & \multirow[t]{2}{*}{8} & \multirow{2}{*}{$\begin{array}{c}\text { DISPOR COLABORADORES } \\
\text { COMPROMETIDOS, MOTIVADOSE } \\
\text { COMPETENTES }\end{array}$} & \multirow{2}{*}{$\begin{array}{l}10096 \text { DAS } \\
\text { INICIATIVAS DENTRO } \\
\text { DA META }\end{array}$} & 1 & $\begin{array}{c}\text { OBTER PERCENTUAL DE } \\
\text { COLABORADORES TREINADOS X } \\
\text { PLANEJADO }>=9396\end{array}$ & $75 \%$ \\
\hline & & & & 2 & $\begin{array}{c}\text { OBTER EM } 2010 \text { TAXA DE } \\
\text { FREQUÊNCIA DE ACIDENTES }<=11 \\
\text { ACIDENTES }\end{array}$ & TAXA DE FREQUÊNCIA DE ACIDENTES \\
\hline
\end{tabular}

Fonte: Adaptado empresa Beta (2010) 
Perspectiva financeira: até o mês de setembro de 2010 foi atingido o EBITDA em $65 \%$, em virtude das varáveis externas ocorridas no período, as quais interferiram no preço da matéria prima alterando o custo e o preço de venda do produto. Por este fator ter interferido não somente na empresa Beta, mas em todas as empresas do ramo, a meta foi atingida muito próxima a sua totalidade. Os custos médios de produção alcançaram a meta de $89 \%$, pelo fato da alta dos preços da matéria prima. Já o preço médio líquido alcançou a meta de $96 \%$ em virtude da alta dos custos, os preços dos produtos aumentaram no mercado, permitindo assim atingir a meta desejada.

As despesas operacionais administrativas estão dentro das metas e atenderam as expectativas no período analisado. As despesas operacionais comerciais ligadas ao setor de vendas, também estão dentro das metas desejadas. Embora tenha havido um aumento no ciclo operacional em virtude da demora para a fabricação do produto por falta de matéria prima, as demandas dos produtos fabricados foram atendidas sem gastos extraordinários, assim essas despesas não alteraram permitindo que as metas esperadas sejam atendidas.

Perspectiva de clientes: em virtude da percepção de que as vendas estavam concentradas em alguns clientes ocorreu a necessidade da abertura e a busca de novos clientes para desconcentrar essas vendas. Assim, a empresa buscou a desconcentração de $80 \%$ das vendas em $34 \%$ dos clientes, o indicador mostra que até o mês de setembro do referido ano essa meta foi atingida em $77 \%$.

$\mathrm{O}$ atendimento das reclamações de clientes baseados nas especificações dos produtos e prazos de entrega atendeu em $65 \%$ da meta estipulada. O processo de pesquisa de satisfação de clientes atingiu $64 \%$ até o final do mês de setembro. Devido às iniciativas e avaliações trimestrais, poderia haver aumentos desse percentual até o final do referido ano.

Perspectiva de processos internos: na produção do papel o objetivo estratégico de obtenção de produção efetiva foi de $86 \%$, onde foram alcançados $75 \%$ dessa meta ocasionado pelas reclamações não atendidas em tempo. Para atender o objetivo estratégico de $86 \%$ da produção efetiva, seriam necessárias as iniciativas de implementação do TPM na produção, para que as máquinas produtivas mantenham $100 \%$ da sua capacidade operacional.

Para que o prazo de entrega seja atendido com eficácia é necessário que a produção cumpra o prazo programado e que o comercial realize as vendas e as efetive com a produção programada. $\mathrm{O}$ aumento na produção busca a realização de novos clientes para cumprir a meta, encobrindo o aumento dos custos da matéria prima. Dentro do cronograma realizaram-se os prazos de produção e de vendas em $70 \%$.

Perspectiva de aprendizado e crescimento: a perspectiva de aprendizado e crescimento na unidade papel tem por objetivo a certificação da ISO 9001/2008. Para isto, é necessária toda documentação da qualidade, produção, comercial, suprimentos e recursos humanos. A certificação deveria ocorrer até o final do período e conforme a auditoria interna da ISO 9001, a documentação 
foi encaminhada e a empresa estava aguardando a auditoria externa.

A empresa busca diminuir a taxa anual de frequência de acidentes no trabalho, para isso é incentivada à utilização de equipamentos de segurança, entre outros planos de incentivo para que os acidentes não ocorram. Na perspectiva de aprendizado e crescimento, a iniciativa determinada na empresa para o ano de 2010 era de até 11 acidentes, e até o mês de setembro ocorreram 15 acidentes. Isso leva a empresa a promover ações corretivas relacionadas ao uso de equipamentos de segurança para que esses índices diminuam.

\section{Discussão dos resultados}

Por meio das entrevistas e informações relacionadas aos colaboradores e dos documentos disponibilizados pôde-se observar que, com a busca por uma ferramenta de gestão a empresa Beta passou a definir suas estratégias, planejamento, alinhamento dos temas e a construção de seus mapas estratégicos. Conforme Kaplan e Norton (1997), o mapa estratégico procura resolver os problemas ao fornecer um modelo para uma representação simples, numa única página, apresentando as relações de causa e efeito entre os objetivos e os resultados esperados de acordo com a estratégia.

Ainda, segundo Kaplan e Norton (2000) o alinhamento dos objetivos nas quatro perspectivas colabora com a criação de valor. A construção do mapa estratégico pode fazer com que a organização esclareça a lógica de como e para quem ela criará valor. O mapa estratégico fornece uma maneira uniforme e consistente de descrever a estratégia, facilitando a definição e o gerenciamento dos objetivos e indicadores.

A coordenação da gestão do conhecimento pode ser atingida por meio da criação, do compartilhamento e da aplicação do conhecimento, assim como, pela incorporação de lições aprendidas e melhores práticas dentro empresa como um todo, objetivando sustentar a aprendizagem organizacional continuamente. A partir dos resultados obtidos até o mês de setembro de 2010, foi possível identificar as iniciativas que necessitam serem melhoradas e implementadas de acordo com as ações da gestão do conhecimento.

Conforme entrevista realizada com o coordenador do Sistema Integrado de Gestão da empresa, a alta direção e os colaboradores vêm demonstrando comprometimento com a organização. Esse fato sinaliza que a empresa Beta potencializa a aplicação da gestão do conhecimento, o que propicia uma interpretação dinâmica do conhecimento, considerando as particularidades estratégicas para a melhoria do estado econômico, mercadológico, tecnológico, operacional e social da empresa. Conforme Vergara (2000) o comprometimento dos colaboradores propicia o entendimento da natureza dos processos e produzem efeitos consideráveis no alcance dos objetivos organizacionais. 
De acordo com os dados coletados, a empresa faz uso do EBITDA para critérios de avaliações. Este critério se justifica por mostrar a preocupação no uso de indicadores abordados por diversas empresas nas divulgações externas, ampliando seu leque de comparações nas análises.

Com a utilização do EBITDA, não há influência da legislação tributária, nem de políticas de depreciação. Por se mostrar eficaz nas análises das empresas, o EBITDA é um misto de indicador de desempenho econômico e financeiro, o que ressalta sua importância.

O resultado financeiro da empresa Beta apresentou $65 \%$ da meta durante o período analisado. Tal fato ocorreu, por alguns fatores externos que contribuíram para que a empresa não atingisse a proporcionalidade da meta desejada até o final de setembro. Segundo a Associação Brasileira de Celulose e Papel, o setor de celulose no Brasil enfrentou inúmeras dificuldades no ano de 2009 por causa da crise mundial que afetou também a indústria de papel (BRACELPA, 2010).

De acordo com o gerente financeiro da empresa Beta, os fatos ocorridos influenciaram nos resultados na indústria brasileira, de forma que a empresa não atingiu suas metas financeiras com eficácia. Entretanto, esses fatores internos deveriam ter sido previstos, uma vez que as empresas normalmente preveem fundos destinados a perdas, especialmente as indústrias dependentes de máquinas e de outras empresas, sem contar com as rendas decorrentes de clientes que nem sempre honram suas dívidas. Porém, com a definição dos temas estratégicos de gestão de risco, a empresa projetou apenas indicadores para medição de desconcentração de vendas. A prevenção dos fatores externos que interferem nos custos pode ser minimizada a partir do momento que os processos internos considerarem as variáveis externas, prevenindo qualquer variação nos preços das matériasprimas.

A eficácia na gestão pode ser aumentada com a avaliação do risco estratégico que é um conjunto de condições que reduzem significativamente sua capacidade de implementar a estratégia do negócio considerando as ameaças e oportunidades. Assim, a identificação de oportunidades poderá considerar os riscos a elas associados de forma que os objetivos estratégicos poderão corresponder a uma descrição clara dos riscos inerentes, possibilitando à empresa se programar para fatos que poderão surgir.

A Gestão do Conhecimento pode complementar a visão do gerenciamento de risco, focando estrategicamente o conhecimento organizacional. A utilização de técnicas de gestão do conhecimento que atendam uma posição de tolerância de risco nos diversos níveis pode vir a desenvolver um perfil dos riscos inerentes à organização e desse modo, ajudar a decidir que riscos devem ser administrados (ROCQUE, 2007).

Na perspectiva de aprendizado e crescimento, a empresa atentou-se para o tema estratégico capital humano, tratando da identificação e introdução de iniciativas para contratação, desenvolvimento, motivação e retenção de forças de trabalho. Essa perspectiva implica o 
recrutamento para obter funcionários com maior capacidade analítica. Segundo Sveidy (1998) o recrutamento de novos funcionários é a decisão de investimento mais relevante da gerência e talvez, a sua ferramenta estratégica mais importante. Isso mostra que programas destinados aos funcionários, no sentido de melhorar suas atuações, tanto para novas contratações como na educação continuada e suas capacidades criativas, podem ser alinhadas com os objetivos da organização.

Esse diferencial competitivo no mundo corporativo pode estar diretamente relacionado ao conhecimento gerado entre os colaboradores da organização. As empresas podem se beneficiar com os resultados das práticas da gestão do conhecimento como ferramenta de gestão, integrando de forma dinâmica com os objetivos estratégicos.

\section{Conclusão}

Os resultados obtidos mostram que o alinhamento da ferramenta de gestão BSC e a Gestão do Conhecimento trazem melhorias contínuas para a eficácia dos resultados desejados nas propostas estratégicas desenvolvidas pela alta direção. O conjunto de indicadores relacionados à Gestão do Conhecimento elaborados e ordenados nas diversas perspectivas, ligados aos objetivos da empresa permite um controle mais amplo e efetivo, possibilitando desta forma que os colaboradores da empresa possam conhecer as estratégias e resultados esperados, como também as suas relações de causa e efeito.

O BSC foi baseado nos conceitos das relações de causa e efeito, mas observaram-se limitações em sua construção, que podem ser superadas pela aplicação da gestão do conhecimento, trabalhando com categorias mais abrangentes de forma que o conhecimento atinja a todos os colaboradores da empresa.

Verificou-se também, que a utilização desta metodologia de alinhamento na prática não é tão simples, pois determinar o nível de alinhamento depende do convencimento e aceitação da alta direção, um pouco rígida na aceitação de novas propostas. A empresa estudada deve ampliar os estudos na ferramenta do Balanced Scorecard, buscando a melhoria contínua dos processos de criação dos indicadores, demonstração dos mapas estratégicos e disseminação de seus resultados, assim como a divisão dos mapas de cada unidade do grupo. Também deve ser considerada a promoção de ações da gestão do conhecimento como complemento ao BSC, ampliando assim o comprometimento dos seus colaboradores.

Assim ocorre a criação de uma organização capacitada a responder com rapidez as mudanças do mercado estando mais alinhada e consequentemente melhorando a consistência estratégica da organização. 


\begin{abstract}
This study evaluates the methodology of the Balanced Scorecard to align with the management of knowledge, aiming at improving the quality of management. Uses search exploratory and descriptive, with quantitative and qualitative approach, and as for the technical procedures, is considered a literature search in which we used primarily the contributions of several authors on the subject and documentary, by using information gathered through not structured interviews and informal and in company documents studied. The survey was conducted in an Industry Group, comprised of three companies, focusing on the paper industry, here called Beta Company. This company has the BSC as a management tool of the strategy, which led to the study. After completion of data collection, it was possible to analyze the documents and verify the importance of alignment of Knowledge Management with the BSC tool. Points were identified for dissemination of knowledge, it is possible and necessary, establish new goals and strategic actions for the company under study. It was found that application of the BSC method, showed the feasibility of adaptation with the Knowledge Management for the type of company under study, as well as the influences in different perspectives. The set of indicators related to Knowledge Management prepared and ranked in several perspectives, linked to business objectives, will allow a more controlled and effective, thus enabling the company's employees stay aware of the strategies and expected results, as well as their relations of cause and effect. Thus, the study emphasizes the corporate instrumentation can take place the conversion of individual knowledge into strategic continuously. Organizations must be prepared for new challenges, and Knowledge Management is open for organizations to manage their deployment environments.
\end{abstract}

Key-words: strategic management, knowledge management, balanced scorecard.

\title{
Referências
}

ANTHONY, R.; GOVINDARAJAN, V. Sistemas de controle gerencial. São Paulo. Atlas. 2002.

BRACELPA. Associação Brasileira de Celulose e Papel. São Paulo. 2010. Disponível em: http://www.bracelpa.org.br/bra2/?q=node/196. Acesso em: 16 ago. 2011.

CASTILLO, L. A. M.; CAZARINI, E. W. Modelo integrado para a implantação da gestão do conhecimento. In: SIMPÓSIO DE ENGENHARIA DE PRODUÇÃO, 16, 2009, Bauru. Anais... Bauru: UNESP, 2009.

DAVENPORT, T; PRUSAK, L. Conhecimento empresarial. Rio de Janeiro: Campus, 1998.

FAIRCHILD, A. M. Knowledge management metrics via a balanced scorecard methodology. Proceedings...of the 35th Hawaii International Conference on System Sciences, 2002

FARROQ, A.; HUSSAIN, Z. Balanced scorecard perspective on change and performance: a study of selected Indian companies. Procedia - Social and Behavioral Sciences, V: 24, P: 754-768, 2011

KAPLAN, R. S.; NORTON, D. P. A estratégia em ação: Balanced Scorecard. 9. Ed. Rio de Janeiro: Campus, 1997.

Organização orientada para a estratégia: como as empresas que adotam o Balanced Scorecard prosperam no novo ambiente de negócios. Rio de Janeiro: Campus, 2000.

The Strategy-Focused Organization: How Balanced Scorecard companies thrive in the new business environment. Harvard Business School Publishing Corporation, USA. 2001.

KRONMEYER FILHO, O. R. Gestão estratégica e BSC: gaps e oportunidades de melhoria. In.: XXIV ENCONTRO NACIONAL DE ENGENHARIA DE PRODUÇÃO, 24, 2004, Florianópolis. Anais... Florianópolis :ABEPRO, 2004;

LANBERG, J.; PARVINEN, P. The river metaphor for strategic management. European Management Journal, V: 21, n: 5, p: 549-557, 2003.

GAO, F.; LI, M.; CLARKE, S. Knowledge, management, and knowledge management in business operations. Journal 
of Knowledge Managment, V: 12, n:2, p: 3-17, 2008.

MINTZBERG, H.; LAMPEL J.; AHSLTRAND, B. Safári de estratégia: um roteiro pela selva do planejamento estratégico. Porto Alegre: Bookman, 2000.

MINTZBERG, H.; QUINN, J. B. The strategy process: concepts, contexts and cases. Englewood Cliffs: 2. ed. Prentice-Hall International, 1991.

MONTGOMERY, C. A.; PORTER, M. E. Estratégia: a busca da vantagem competitiva (introdução). Rio de Janeiro: Campus, 1998.

PORTER, M. E. Competição: estratégias competitivas essenciais. 4. ed. Rio de Janeiro: Campus, 1999.

ROCQUE, E.L. Guia de orientação para o gerenciamento de riscos corporativos. IBGC. São Paulo. 2007. Série de Cadernos de Governança Corporativa, 3.

SVEIBY, K. E. A Nova riqueza das organizações: Gerenciando e Avaliando Patrimônios de Conhecimento. Rio de Janeiro: Campus, 1998.

TERRA, J. C. C. Gestão do conhecimento: 7 dimensões e 100 práticas. Terra Fórum Consultores. 2007

VASCONCELOS, Y. L. EBITDA como instrumento de avaliação de empresas. Revista Brasileira de Contabilidade. N: 136, p. 39-47, jul./ago: 2002.

WRIGHT, P.; KROLL, M.; PARNELL, L. Administração estratégica: conceitos. São Paulo: Atlas, 2000.

WANG, L.; ZHANG, H.; ZENG, Y. Fuzzy analytic hierarchy process (FAHP) and balanced scorecard approach for evaluating performance of Third-Party Logistics (TPL) enterprises in Chinese context. African Journal of Business Management, V: 6, n:2, p: 521-529, Jan, 2012.

\section{Dados dos autores:}

\section{Nome completo: Rita de Cássia Fonseca}

Filiação institucional: Universidade Estadual do Centro-Oeste - UNICENTRO

Departamento: Ciências Contábeis

Função ou cargo ocupado: Professor

Endereço completo para correspondência (bairro, cidade, estado, país e CEP): Rua Padre Salvador, 875 - CEP 85015-430 - Guarapuava-PR

Telefones para contato: (42) 3621-1000

e-mail: ritadecfonseca@hotmail.com

\section{Nome completo: Marcia Danieli Szeremeta Spak}

Filiação institucional: Universidade Tecnológica Federal do Paraná - UTFPR

Departamento: Programa de Pós-graduação em Engenharia de Produção - PPGEP

Função ou cargo ocupado: Bolsista de mestrado

Endereço completo para correspondência (bairro, cidade, estado, país e CEP): Av. Monteiro

Lobato, s/n, Campus Universitário, Ponta Grossa, Paraná, Brasil, CEP: 84.015-480

Telefones para contato: (42) 3220-4805 
e-mail: marciaspak@yahoo.com.br

Nome completo: Camila Clivati Justus

Filiação institucional: Universidade Tecnológica Federal do Paraná - UTFPR

Departamento: Coordenação de Engenharia de Produção em Controle e Automação - COELE Função ou cargo ocupado: Bolsista de Iniciação Científica

Endereço completo para correspondência (bairro, cidade, estado, país e CEP): Av. Monteiro

Lobato, s/n, Campus Universitário, Ponta Grossa, Paraná, Brasil, CEP: 84.015-480

Telefones para contato: (42) 3220-4805

e-mail: milajustus@hotmail.com

Nome completo: João Carlos Colmenero

Filiação institucional: Universidade Tecnológica Federal do Paraná - UTFPR

Departamento: Programa de Pós-graduação em Engenharia de Produção - PPGEP

Função ou cargo ocupado: Professor do Programa de Pós-graduação em Engenharia de Produção e

Coordenador do Curso de Engenharia de Produção

Endereço completo para correspondência (bairro, cidade, estado, país e CEP): Av. Monteiro

Lobato, s/n, Campus Universitário, Ponta Grossa, Paraná, Brasil, CEP: 84.015-480

Telefones para contato: (42) 3220-4805

e-mail: colmenero@utfpr.edu.br

Enviado em: 07/10/2011

Aprovado em: 08/03/2012 